\section{Estudo \\ CoDebate}

em Testão

Planejamento

\title{
CARACTERIZAÇÃO E ANÁLISE DOS RESÍDUOS DE EMBALAGENS GERADOS NA PRODUÇÃO DE REFEIÇÓES DE UM HOSPITAL PÚBLICO DE PORTO ALEGRE, RS
}

\author{
Aline Veiga dos Santos ${ }^{1}$, Virgílio José Strasburg ${ }^{2}$
}

\begin{abstract}
Resumo: Serviços de alimentação originam muitos resíduos, incluindo embalagens de alimentos, que causam danos ao meio ambiente. Este estudo objetivou quantificar e analisar os resíduos de embalagens na produção de refeiçóes de um hospital público de Porto Alegre, RS. Foram selecionados, pela curva ABC, os alimentos que somaram $90 \%$ do consumo de março a junho de 2015. Cinco amostras de embalagens de cada item foram pesadas. Os cálculos foram realizados no programa Microsoft Office Excel 2010. O total de resíduos gerados foi estimado em $2.710,6 \mathrm{~kg}$, sendo $56 \%$ de plásticos e $26,8 \%$ de metal. Ao diminuir-se o uso especialmente de produtos com embalagens plásticas, que geram as maiores quantidades de resíduos, e reconsiderar-se a oferta de alimentos de baixo valor nutricional, os impactos ambientais negativos observados neste estudo podem ser reduzidos.
\end{abstract}

Palavras-chave: Alimentos. Manejo de resíduos. Unidades de Alimentaçâo e Nutrição.

\section{CHARACTERIZATION AND ANALYSIS OF PACKAGING WASTE GENERATED IN MEAL PRODUCTION FROM A PUBLIC HOSPITAL IN PORTO ALEGRE, RS}

\begin{abstract}
Food services produce a lot of waste, including food packages, which can cause damage to the environment. This study aimed to quantify and analyze the packaging waste generated in meal production from a public hospital in Porto Alegre, RS. Foodstuffs that, according to the ABC analysis, added up to $90 \%$ of the consumption between March and June 2015 were selected for the research. Five package samples of each item were weighed. The calculations were made with Microsoft ${ }^{\bullet}$ Office Excel 2010. The total of waste generated was estimated to be $2.710,6 \mathrm{~kg}$, where $56 \%$ was plastic, and $26.8 \%$ was metal. By lowering the usage especially of products with plastic packaging, which generate the largest amounts of waste, and reassessing the offer of foods of low nutritional value, the negative environmental impacts observed in this study can be reduced..
\end{abstract}

Keywords: Foods. Waste management. Food and Nutrition Units.

1 Graduação em Nutrição, Faculdade de Medicina, Universidade Federal do Rio Grande do Sul.

2 Doutor em Qualidade Ambiental. Professor Adjunto, Departamento Nutrição, Faculdade de Medicina, Universidade Federal do Rio Grande do Sul. 


\section{INTRODUÇÁO}

$\mathrm{O}$ ato de comer fora do domicílio tem se tornado cada vez mais prevalente entre a população (LAMBERT et al., 2005; LEAL, 2010). Essa demanda é atendida por serviços de alimentação, também chamados de Unidades de Alimentaçáo e Nutrição (UANs). Nas UANs, é realizada uma sequência de açóes com o objetivo de fornecer refeiçóes para coletividades (ABREU; SPINELLI, 2013). Em linhas gerais, as UANs costumam ser classificados em duas modalidades: 1) comerciais - que incluem restaurantes, lanchonetes, cafés, bares, entre outros; e 2) institucionais - que abarcam o atendimento para escolas, hospitais, empresas, forças armadas, entre outros (EDWARDS, 2013). Essas refeiçōes devem obedecer a certos padróes dietéticos e higiênicos, suprindo as necessidades nutricionais e contribuindo para manter ou recuperar a saúde do público atendido (ABREU; SPINELLI, 2013; COLARES; FREITAS, 2007). Ao realizar suas atividades, as UANs utilizam energia elétrica e água em elevadas quantidades e geram um grande volume de resíduos, podendo afetar negativamente o meio ambiente (SPINELLI, 2013; VENZKE, 2001).

No final do século XX, aguçou-se a percepçáo acerca dos impactos ambientais, bem como do papel da sociedade em relação ao meio ambiente (VAN BELLEN, 2004). Diversos tipos de organizações vêm demonstrando interesse em alcançar um desempenho ambiental correto (ABNT, 2004). A Lei no 12.305 de 2010, instituiu no Brasil a Política Nacional de Resíduos Sólidos (PNRS), que compreende um conjunto de princípios, instrumentos, diretrizes, metas e açôes que visam a gestáo e o gerenciamento adequados dos resíduos. Seus objetivos incluem o estímulo à adoção de padrōes sustentáveis de produção e consumo de bens e serviços, o incentivo à indústria da reciclagem e à implantação da avaliação do ciclo de vida do produto, entre outros. De acordo com o artigo $9^{\circ}$ da PNRS, deve-se obedecer à seguinte ordem de prioridades no manejo de resíduos: 1) não geração; 2) redução; 3) reutilização; 4) reciclagem; 5) tratamento; e 6) disposiçáo final adequada dos resíduos que esgotarem todas as possibilidades de tratamento e recuperação, denominados rejeitos (BRASIL, 2010).

O conjunto de práticas adotadas por uma empresa ou indústria visando reduzir os danos causados por suas atividades sobre o meio ambiente denomina-se gestão ambiental (POSPISCHEK; SPINELLI; MATIAS, 2014). Compete ao profissional de nutrição, como gestor de uma UAN, definir estratégias para reduzir a utilização de recursos naturais e a geração de resíduos (SPINELLI, 2013). A American Dietetic Association (ADA) orienta os profissionais nutricionistas que atentem à sua responsabilidade ambiental, trabalhando para a redução dos resíduos e do desperdício de alimentos, e incorporando açóes como reciclagem de óleos de fritura e coleta seletiva de resíduos recicláveis, entre outras (ADA, 2007). Os resíduos gerados em UANs incluem materiais de escritório, itens descartáveis, embalagens de matérias-primas, produtos vencidos, partes não comestíveis de alimentos, óleos utilizados para fritura e alimentos preparados, mas não utilizados (SPINELLI, 2013).

O fluxo de resíduos de embalagens é relativamente pequeno, mas não é insignificante, e seus impactos ambientais correspondem à grandeza de um a alguns pontos percentuais $\mathrm{da}$ economia global (COM, 2006). Os resíduos de embalagens são preocupantes pelo volume que ocupam nos aterros sanitários e por seus materiais constituintes (CAPELINI, 2007). No estabelecimento de estratégias para o correto gerenciamento dos resíduos, é necessário 
que se conheçam suas características, como os tipos de resíduos gerados e suas quantidades (CNTL, 2003; FARMER, 1997; SMYTH, 2010). Os estudos de caracterização de resíduos podem motivar iniciativas de sustentabilidade (SMYTH, 2010).

Os processos decorrentes da produção de refeiçóes causam impactos no meio ambiente e também sob o enfoque econômico (HARMON; GERALD, 2007). Nesse contexto, é inerente a ocorrência da geração de resíduos, que podem ser procedentes de embalagens que acondicionam os vários tipos de alimentos ou de produtos químicos, que são usados de maneira direta ou indireta na produção de refeiçóes. São listados como principais materiais papéis, papelóes, plásticos, vidros, latas e embalagens cartonadas para esse segmento (WANG, 2012; GRAU, 2015).

À vista disso, este estudo investigou a caracterização, a tipificação e a quantificação dos resíduos de embalagens relacionados com os alimentos utilizados na produçáo de refeições (almoço e jantar) no Serviço de Nutrição e Dietética (SND) de um hospital público federal de Porto Alegre, RS. Esse tipo de investigação se justifica pela relevância da atividade de produção de refeições, seja privada ou pública, bem como da avaliação dos impactos das embalagens ao meio ambiente. $\mathrm{O}$ segmento de fornecimento de refeiçóes no Brasil, segundo informaçóes da Associação Brasileira das Empresas de Refeições Coletivas (ABERC), forneceu por meio de empresas com autogestão, refeiçóes coletivas e refeiçôes por convênio, mais de 19,68 milhóes de refeiçóes/dia, no ano de 2014 (ABERC, 2015).

\section{MÉTODO}

O estudo foi submetido na Plataforma Brasil e aprovado pela Comissão de Pesquisa da Faculdade de Medicina da Universidade Federal do Rio Grande do Sul, sob o no 29759. É um estudo retrospectivo, no setor de produção de refeições do hospital, utilizando-se dados, por critério de conveniência, do período compreendido dos meses de março a junho de 2015 .

Quanto ao método, este estudo é do tipo observacional. Gil (2008) destaca que "no estudo por observação, apenas observa algo que acontece ou já aconteceu”. O mesmo autor também pondera que o método observacional "pode ser considerado como o mais primitivo e, consequentemente, o mais impreciso. Mas, por outro lado, pode ser tido como um dos mais modernos, visto ser o que possibilita o mais elevado grau de precisão nas ciências sociais" (GIL, 2008).

O SND oferece refeições para funcionários, pacientes e seus acompanhantes, e aos filhos dos funcionários atendidos na creche do hospital. De acordo com informaçóes obtidas no local, através de entrevistas e consultas às fichas técnicas de preparação, o número estimado de refeiçóes principais (almoço e jantar) é de 5.312 em dias úteis, 3.082 aos sábados e 2.982 aos domingos. O cardápio elaborado pelo SND do hospital apresenta a seguinte composição: cereal (arroz), leguminosa (feijão ou lentilha), guarnição (hortaliças ou gêneros industrializados secos), proteína animal (carne bovina, ave, suína, peixe e derivados), saladas (hortaliças), sobremesa (frutas ou elaboradas) e suco (industrial).

Fez-se listagem dos gêneros alimentícios utilizados nos cardápios de almoço e jantar oferecidos para funcionários e pacientes do hospital. Não foram incluídos hortifrútis in 
natura, por não serem geradores de resíduos de embalagens; nem itens com apresentação em sachês individuais, que são utilizados apenas para fins específicos em alguns tipos de dietas para pacientes. Após a montagem da lista, os itens foram divididos nos seguintes grupos: carnes, acompanhamentos, guarniçóes, saladas, itens complementares, sobremesas e bebidas. Alimentos passíveis de serem incluídos em mais de um grupo (hortifrútis usados tanto em saladas como guarniçóes) foram listados no grupo em que apareciam com maior frequência nos cardápios. Produtos usados como ingredientes em preparaçôes foram classificados como itens complementares.

Com os códigos de material de cada item, obtidos junto ao setor de estoque do SND, foi realizada uma pesquisa no software próprio e específico do hospital, para averiguar o consumo total de cada um dos itens durante o período do estudo. Os dados de consumo foram ajustados para quilogramas $(\mathrm{kg})$ ou litros $(\mathrm{L})$, de acordo com a natureza de cada produto. Os itens foram, então, classificados pelo critério da curva $\mathrm{ABC}$, no qual os materiais são selecionados de acordo com sua importância e quantidades utilizadas (CARVALHO, 2002). A escolha pela utilização da curva $A B C$ foi decorrente da identificação de uma quantidade elevada de itens utilizados, porém com baixa frequência de consumo. Foram selecionados para o estudo aqueles que representavam $90 \%$ do consumo de cada grupo de alimentos, por serem mais representativos sob o aspecto quantitativo. A relação dos itens utilizados está descrita no Quadro 1.

Quadro 1 - Relação de itens selecionados por grupo de alimentos. Porto Alegre-RS, 2015

\begin{tabular}{|l|l|c|}
\hline Grupo de alimentos & \multicolumn{1}{|c|}{ Relaçáo de itens } & Total de itens \\
\hline Carnes & $\begin{array}{l}\text { Bovina: bife, cubos, moída, picado e iscas; frango: filé, } \\
\text { coxa, sobrecoxa e cubos; peixe: filé. }\end{array}$ & 10 \\
\hline Acompanhamentos & Arroz branco, feijão preto e arroz integral. & 3 \\
\hline Guarnições & $\begin{array}{l}\text { Hortifrútis higienizados: chuchu, batata, moranga cabotiá, } \\
\text { espinafre, abóbora e couve manteiga; } \\
\text { produtos frescos: massa ravióli; } \\
\text { produtos secos: massas espaguete e penne. }\end{array}$ & 9 \\
\hline Saladas & $\begin{array}{l}\text { Hortifrútis higienizados: cenoura, alface, couve-flor, } \\
\text { beterraba, brócolis, vagem e rúcula. }\end{array}$ & 7 \\
\hline $\begin{array}{l}\text { Itens } \\
\text { complementares }\end{array}$ & $\begin{array}{l}\text { Hortifrútis higienizados: cebola; laticínios: margarina, } \\
\text { queijo inteiro, iogurte natural, queijo ralado, leite } \\
\text { pasteurizado; produtos secos e enlatados: sal refinado, } \\
\text { farinha de trigo, amido de milho, farinha de milho, milho } \\
\text { em conserva, ervilha em conserva éleo de soja. }\end{array}$ & 13 \\
\hline Sobremesas & Pudim, gelatina, pêssego e figo em calda, gelatina diet, sagu. & 6 \\
\hline Bebidas & Refresco concentrado. & 1 \\
\hline
\end{tabular}

A caraterização das embalagens de cada produto foi feita com base no conteúdo e tipologia (material constituinte) e, após, a pesagem de cinco (5) amostras de embalagens, bem como do fardo, caso houvesse. Utilizou-se uma balança eletrônica da marca Filizola ${ }^{\mathrm{T}}$, 
com precisão de $1 \mathrm{~g}$ e capacidade de $3 \mathrm{~kg}$. Quando necessário, as embalagens foram lavadas com água e sabão líquido e secas com pano de prato, para a retirada de líquidos ou partículas de alimentos. Os valores dos pesos das amostras foram introduzidos em tabela do software Microsoft ${ }^{\oplus}$ Office Excel 2010, onde se fez o cálculo das médias e do coeficiente de variação. Foi selecionado para utilização nas análises o valor mais prevalente entre as amostras (moda). Determinado o peso de cada embalagem a ser usado nas análises, foram feitos no Microsoft ${ }^{\circ}$ Office Excel 2010 os cálculos do total e do percentual da geração de resíduos de embalagens, por grupo de alimentos e por tipologia de embalagem.

Em relação as suas limitações, destacam-se duas situações. A primeira está relacionada com o período restrito de investigaçáo; um período maior poderia dar mais consistência aos resultados. A segunda foi a opção de se selecionar somente os resíduos de embalagens de produtos alimentares e, dessa forma, apenas uma das partes de um processo - isso porque, na produção de refeiçôes, podem ser avaliados também aspectos de pós-consumo como o uso de produtos descartáveis e de produtos de higiene e limpeza. No entanto, essa escolha se explica pelo fato de ser no planejamento de cardápios e na escolha dos insumos a possibilidade de se trabalhar o aspecto mais preventivo do processo da geração de resíduos de embalagens.

\section{RESULTADOS E DISCUSSÃO}

A Tabela 1 apresenta a quantidade de itens selecionados para o estudo, por grupo de alimentos; e os totais de: consumo em quilogramas $(\mathrm{kg})$ no período estudado; quantidade de resíduos de embalagens gerados por cada um.

Tabela 1 - Quantidade de itens e totais de consumo e de resíduos de embalagens por grupo de alimentos. Porto Alegre, RS, 2015

\begin{tabular}{rccc}
\hline Grupos de alimentos & $\begin{array}{c}\text { Quantidade de } \\
\text { itens }\end{array}$ & $\begin{array}{c}\text { Consumo mar- } \\
\text { jun/2015 (kg) }\end{array}$ & $\begin{array}{c}\text { Resíduos de embalagens } \\
(\mathbf{k g})\end{array}$ \\
\hline Carnes & 10 & 67.487 & 181,2 \\
\hline Acompanhamentos & 3 & 31.738 & 167,5 \\
\hline Guarniçóes & 9 & 35.697 & 223 \\
\hline Saladas & 7 & 26.414 & 304,1 \\
\hline Itens complementares & 13 & 44.011 & 1.246 \\
\hline Sobremesas & 6 & 1.507 & 101,5 \\
\hline Bebidas & 1 & 7.796 & 487,4 \\
\hline Total & 49 & 214.651 & $2.710,60$
\end{tabular}

Considerando o total de dias do período estudado (122) e os dados obtidos no local, a média diária de refeiçóes (almoço e jantar) oferecidas pelo SND foi estimada em 4.657. Assim, o total de resíduos de embalagens gerados $(2.710,6 \mathrm{~kg})$ representa uma média diária 
de 22,2 kg e um per capita de cinco gramas (g) de resíduos por refeição. De acordo com dados fornecidos pela Comissão de Gestão Ambiental (CGA) do hospital, a geração média semanal de resíduos recicláveis é de $8.389,8 \mathrm{~kg}$, o equivalente a $1.198,5 \mathrm{~kg}$ por dia. Desse número, a quantidade diária de resíduos de embalagens estimada neste estudo correspondeu a 1,85\% desse total. A CGA informou que o hospital realiza segregação de resíduos desde 1990, possuindo atualmente coletores de resíduos, contêineres de transporte e caminháo com plataforma elevatória para adequado manejo dos sacos de resíduos.

Cabe ressaltar que o valor de resíduos encontrado no estudo não representa o total de resíduos recicláveis gerados pelo SND. Não foram incluídos os alimentos oferecidos em refeiçôes menores (café da manhã e lanches); tampouco os itens descartáveis (copos plásticos, pratos de isopor, entre outros), que são utilizados diariamente em grandes quantidades; nem os produtos de limpeza, cuja utilização também é essencial após a produção e consumo de refeições nos processos de higienização de instalaçôes, equipamentos e utensílios, conforme descrito na seção Métodos.

O Gráfico 1 apresenta um comparativo entre os percentuais de consumo de cada grupo de alimentos sobre o total consumido e a geração de resíduos de embalagens.

Gráfico 1 - Percentuais de consumo e de resíduos gerados, por grupo de alimentos

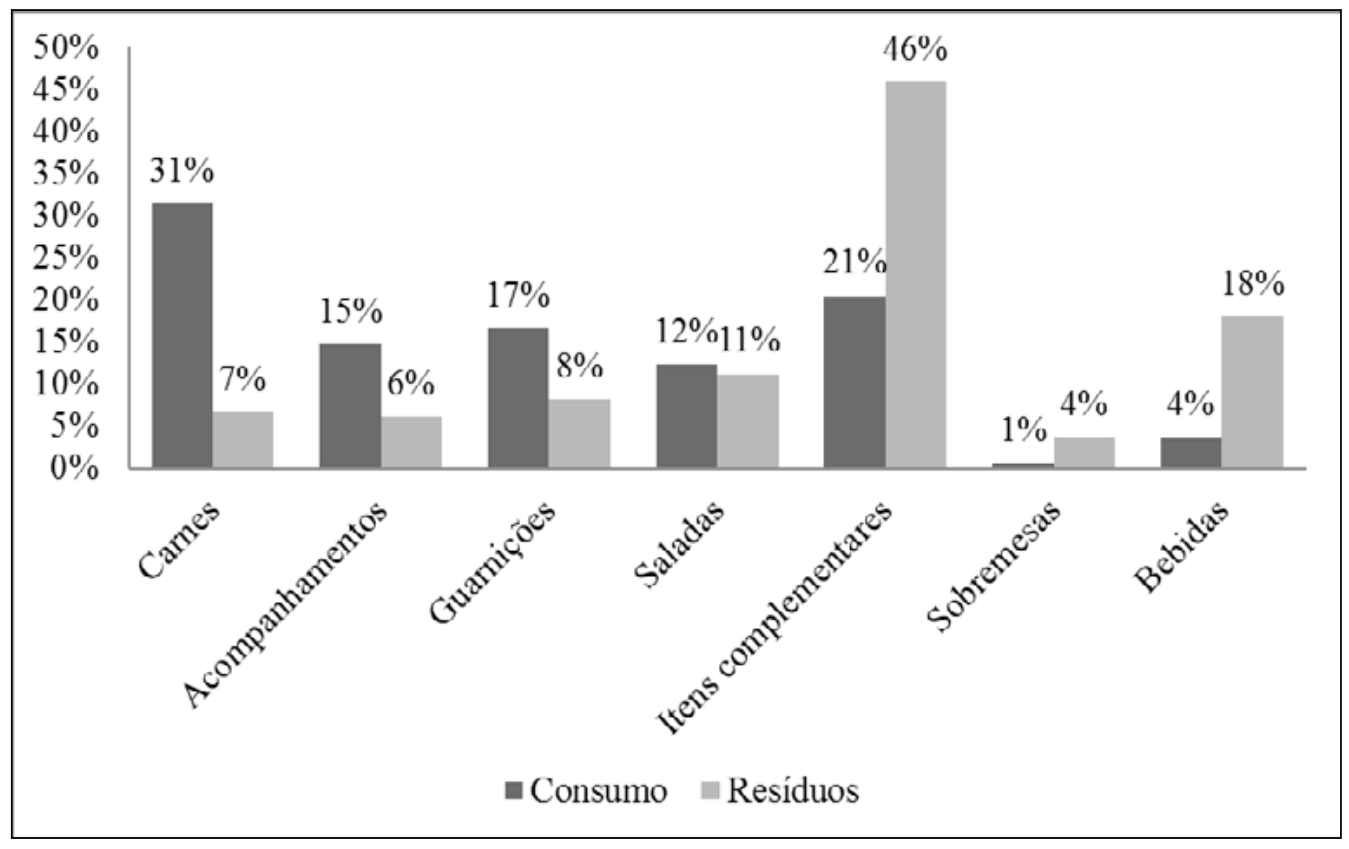

No Gráfico 1, merece ser destacado que os três últimos grupos apresentaram uma relaçáo inversa entre o consumo de produtos alimentares e a sua respectiva geraçáo de resíduos; o percentual de resíduos gerados por esses alimentos sobre o total de resíduos é maior do o percentual de seu consumo sobre o total de alimentos consumidos. A maior porcentagem dos resíduos foi gerada pelos itens complementares e, dentre eles, o maior 
gerador foi o óleo de soja. Esse produto, embalado em latas de 18 litros, contribuiu para $43 \%$ dos resíduos dos itens complementares, $74 \%$ dos resíduos de embalagens metálicas e $20 \%$ do total de resíduos. O consumo desse ingrediente durante o período do estudo foi de 9.810 litros, uma média de 80,4 litros por dia. Considerando as 4.657 refeiçóes diárias estimadas, o per capita de óleo de soja por refeição equivale a aproximadamente 17,26 mililitros.

A Organização Mundial da Saúde (OMS) recomenda que cada pessoa consuma no máximo 16 mililitros (ml) de óleos e gorduras por dia (WHO, 2000 apud CALIXTO et al., 2013). É importante frisar que uma grande parcela do óleo foi utilizada em fritadeiras, e não necessariamente ingerida pelos comensais. De qualquer forma, uma reduçáo nesse volume melhoraria a qualidade nutricional das refeiçóes, diminuiria a quantidade de resíduos, facilitando também o seu descarte adequado. Além disso, o descarte inadequado de óleos vegetais causa impactos ambientais negativos. Se despejados na rede de esgotos, esses produtos poluem a água, criando uma barreira nos rios que compromete a cadeia alimentar aquática e pode aumentar a ocorrência de enchentes. Sua decomposição também emite metano para a atmosfera, contribuindo para o efeito estufa. Alternativamente, alguns destinos possíveis para óleo utilizado em frituras incluem a produção de sabão, de massa de vidraceiro e de ração animal (FERNANDES et al., 2008).

Por sua vez, o refresco concentrado, que é oferecido para os funcionários do hospital em seu refeitório, gerou $18 \%$ do total de resíduos de embalagens, $18 \%$ do total de plásticos e $46 \%$ do total de papeláo/papel. $\mathrm{O}$ consumo desse produto, além de não apresentar benefício dietético, possuindo alto conteúdo de açúcar e corantes, é um grande gerador de resíduos e está ainda associado ao elevado consumo de copos plásticos descartáveis. Assim, visando a melhorar a qualidade nutricional das refeiçōes e reduzir a geração de resíduos, sua oferta deveria ser repensada, considerando como opçóes a sua retirada e o oferecimento apenas de água como alternativa.

Outra opçáo interessante para embalagens de produtos como o óleo de soja e o refresco concentrado seria a logística reversa, definida como o conjunto de açóes, procedimentos e meios que viabilizam a coleta e a restituiçáo dos resíduos sólidos ao setor empresarial (BRASIL, 2010). Seu objetivo é proporcionar, através de um fluxo eficiente e de baixo custo, o reaproveitamento e a recuperação do valor dos resíduos ou o seu descarte ambiente adequado (BRASIL, 2010; ROGERS; TIBBEN-LEMBKE, 1998). A reutilização de embalagens é uma importante estratégia para a redução da geração de resíduos de embalagens (EIMPACK, 2011).

Considerando o aumento nos resíduos e seu impacto no ecossistema, as embalagens retornáveis são uma tendência mundial (LIMA; CAIXETA FILHO, 2001). Além de facilitar o manejo dos resíduos, a logística reversa proporciona vantagem competitiva ao fabricante, pela adequação às questôes ambientais, redução de custo, entre outros fatores (CHAVES et al., 2005). Cabe ressaltar que as embalagens reutilizáveis são mais vantajosas quando as distâncias de transporte são pequenas e as taxas de retorno são elevadas; quando as distâncias são maiores e as taxas de retorno são baixas, as embalagens não reutilizáveis sấo preferíveis (COM, 2006; GOLDING, 1999). 
No contexto industrial brasileiro, um modelo de embalagens retornáveis proposto por Silva et al. (2013), para a exportação de cabeçotes, permitiu uma diminuição de $18 \%$ no consumo de materiais em relaçáo ao modelo de embalagens descartáveis utilizado pela empresa, além de menores custos, maior proteção aos produtos, menor volume de resíduos para o consumidor final e redução do espaço ocupado por embalagens vazias no fluxo reverso. No que diz respeito aos alimentos, a reutilização de embalagens é mais comum na indústria de bebidas (água mineral, refrigerantes, cervejas etc.), mas também está presente, em menor grau, em produtos lácteos, compotas, vinagre e óleo, entre outros (GOLDING, 1999).

O grupo de alimentos que gerou a menor porcentagem dos resíduos de embalagens foi o das sobremesas. No entanto, deve-se destacar que as sobremesas elaboradas são oferecidas apenas para alguns tipos de dietas dos pacientes internados. No atendimento da refeição para os servidores e estudantes do hospital, a sobremesa do cardápio é constituída por frutas in natura, que tem como resíduo apenas material orgânico. Essa constatação corrobora com os achados de Sousa et al, (2012) que afirmam que as embalagens recicláveis não constituem a maioria dos resíduos gerados em serviços de alimentação, sendo eles, em sua maior parte orgânicos (SOUSA et al., 2012).

Carneiro et al. (2010), ao avaliar resíduos em um restaurante universitário no período de um mês, constataram que $90 \%$ dos mesmos eram orgânicos e $10 \%$ inorgânicos. Já Rolim et al. (2011), em pesquisa realizada numa UAN hospitalar durante quatro dias, observaram $77 \%$ de resíduos orgânicos e $23 \%$ de inorgânicos. Em pesquisa bibliográfica realizada por Feil, Spilki e Schreiber (2015), incluindo 44 estudos sobre geração de resíduos sólidos urbanos, demonstrou-se que os resíduos orgânicos constituem a maior porcentagem de resíduos gerados em países desenvolvidos, em desenvolvimento e subdesenvolvidos, com médias de 34,32\%, 61,33\% e 64,21\%, respectivamente.

Quanto às tipologias de embalagem, foram identificados resíduos compostos pelos seguintes materiais: plásticos (sacos, potes e galóes), papelão/papel (caixas e sacos) e metal (latas). Essas tipologias de materiais também foram observadas em resíduos de UANs por diversos autores (CARNEIRO, 2014; CARNEIRO et al., 2010; KINASZ; WERLE, 2008; ROLIM et al., 2011; SOUSA et al., 2012; SOUZA et al., 2009). A Tabela 2 apresenta o total de resíduos de cada tipologia de embalagem gerados por cada grupo de alimentos durante o período do estudo. 
Tabela 2 - Totais de resíduos por tipologias de embalagem, para cada grupo de alimentos (em Kg). Porto Alegre-RS, 2015

\begin{tabular}{rcccc}
\hline Grupos de alimentos & Plásticos (kg) & Papeláo/papel (kg) & Metal (kg) & Total (kg) \\
\hline Carnes & 181,2 & - & - & 181,2 \\
\hline Acompanhamentos & 167,5 & - & - & 167,5 \\
\hline Guarniçóes & 223 & - & - & 223 \\
\hline Saladas & 304,1 & - & - & 304,1 \\
\hline Itens complementares & 359 & 193,6 & 693,4 & 1.246 \\
\hline Sobremesas & 12,6 & 56 & 32,9 & 101,5 \\
\hline Bebidas & 271,9 & 215,5 & - & 487,4 \\
\hline $\begin{array}{r}\text { Resíduos por tipo-logia } \\
\text { de embalagem }\end{array}$ & $1.519,1$ & 465,1 & 726,3 & $2.710,6$ \\
\hline Percentual & $56,0 \%$ & $17,2 \%$ & $26,8 \%$ & $100 \%$ \\
\hline
\end{tabular}

Os hortifrútis higienizados (14 itens, incluindo sacos para embalagens a vácuo e para folhosos) geraram $40 \%$ dos plásticos e $22 \%$ do total de resíduos avaliados no estudo. Isso evoca uma comparaçáo com os produtos in natura, que geram muito pouco ou nenhum resíduo de embalagem. Em contrapartida, os alimentos previamente higienizados proporcionam redução da geração de resíduos orgânicos no setor de pré-preparo e do consumo de água, além de otimização do espaço físico da cozinha, pois se diminui a área destinada à disposição temporária de resíduos (VENZKE, 2001).

Carneiro (2014), em estudo realizado durante 21 dias em um restaurante institucional, observou um total de resíduos de $11.341,33 \mathrm{~kg}$, incluindo resíduos orgânicos e inorgânicos, sendo 2,8\% compostos de latas, $0,2 \%$ de papel/papeláo. Kinasz e Werle (2008), ao avaliar resíduos orgânicos e inorgânicos em sete UANs durante 30 dias, constataram porcentagens variando de $1,16 \%$ a $17,03 \%$ para papel/papelão, e $0,5 \%$ a $16,78 \%$ para latas. Esses autores também relataram a ocorrência de resíduos de embalagens de vidro; esse tipo de embalagem não foi observado no presente estudo. Souza et al. (2009) estudaram os resíduos de um restaurante universitário em dois dias da semana, terça-feira e sexta-feira, e encontraram respectivamente 55,3 kg e 23,77 kg de resíduos; 5,44 kg e 2,58 kg de plásticos; 1,27 kg e $1,13 \mathrm{~kg}$ de papel; $1,08 \mathrm{~kg}$ e 1,02 $\mathrm{kg}$ de metal.

Mais da metade dos resíduos observados neste estudo foi de embalagens plásticas. Esse tipo de embalagem vem sendo utilizada num volume crescente e, devido aos impactos ambientais associados ao seu descarte, sua reciclagem é uma preocupação da sociedade (FORLIN; FARIA, 2002). Muitas embalagens possuem um código indicativo do tipo de plástico do qual são feitas, o que facilita sua adequada identificação, separação e reciclagem (COLTRO; GASPARINO; QUEIROZ, 2008; FORLIN; FARIA, 2002). Em estudo realizado por Ross e Evans (2003), demonstrou-se que a reutilização e a reciclagem de embalagens plásticas têm benefícios significativos para o meio ambiente, reduzindo a 
energia utilizada durante o ciclo de vida da embalagem, já que não há consumo energético para processamento de matéria bruta.

A Tabela 3 mostra o percentual dos resíduos gerados por cada grupo de alimentos sobre o total de resíduos por tipologia de embalagem.

Tabela 3 - Percentuais dos grupos de alimentos sobre o total de resíduos de cada tipologia de embalagem

\begin{tabular}{rccc}
\hline \multicolumn{1}{c}{ Grupos de alimentos } & Plásticos & Papeláo/papel & Metal \\
\hline Carnes & $12 \%$ & $0 \%$ & $0 \%$ \\
\hline Acompanhamentos & $11 \%$ & $0 \%$ & $0 \%$ \\
\hline Guarniçôes & $15 \%$ & $0 \%$ & $0 \%$ \\
\hline Saladas & $20 \%$ & $0 \%$ & $0 \%$ \\
\hline Itens complementares & $23 \%$ & $42 \%$ & $95 \%$ \\
\hline Sobremesas & $1 \%$ & $12 \%$ & $5 \%$ \\
\hline Bebida & $18 \%$ & $46 \%$ & $0 \%$ \\
\hline Total & $100 \%$ & $100 \%$ & $100 \%$ \\
\hline
\end{tabular}

A reciclagem de embalagens já vem sendo utilizada como alternativa para o manejo de resíduos, por ser uma opção mais econômica do que a sua deposição em aterros (COM, 2006; EIMPACK, 2011). Estratégias de reciclagem e reutilização têm por objetivo diminuir o consumo de matérias brutas e o volume de resíduos em aterros (ROSS; EVANS, 2003). Para que o processo de reciclagem seja exitoso, é importante que os resíduos se encontrem no estado mais puro possível (JACOBSEN; KRISTOFFERSEN, 2002).

No local estudado, os funcionários são orientados pelo SND a descartar as embalagens plásticas (sacos) das carnes nas mesmas lixeiras dos demais resíduos recicláveis. Embora essas embalagens sejam de fato recicláveis, na prática elas nem sempre podem ser recicladas devido ao conteúdo de gordura e sangue que permanece em seu interior. Esse conteúdo pode ainda contaminar outros resíduos que teriam maior possibilidade de serem reciclados. A mistura e a contaminação dos resíduos dificultam ou até mesmo impedem sua recuperação e reciclagem (CNTL, 2003).

\section{CONCLUSÃO}

Em qualquer atividade que envolva a produção de refeiçôes, a geração de resíduos vai ocorrer. No entanto, deve ser destacado que, ao contrário do cenário doméstico, para coletividades as açôes de planejamento devem ser consideradas tanto para a elaboração de cardápios (nutricionais) como também nos aspectos ambientais. Nesse contexto, este estudo teve por finalidade a quantificação e a caracterização dos resíduos provenientes das embalagens dos alimentos adquiridos para a produção e fornecimento de refeiçóes em um 
hospital público federal. Os resultados mostraram a estimativa de geração de $2.710,6 \mathrm{~kg}$ de resíduos, potencialmente recicláveis, com $56 \%$ de plásticos e $26,8 \%$ de metal.

A geração de resíduos de embalagens no hospital pode ser diminuída, através de ajustes nas quantidades de ingredientes utilizadas e nos cardápios oferecidos, ponderandose o valor nutricional e o impacto ambiental de cada alimento. A realização de coleta seletiva e o favorecimento à reciclagem, no local estudado, também podem contribuir significativamente para a redução de impactos ambientais que se observam atualmente. Dessa forma, a introduçáo de um novo paradigma na gestão e controle de desperdícios das UANs, além de contemplar açóes voltadas diretamente à saúde de todas as pessoas que aí frequentam, contribuirá para a melhor apresentação e qualidade do meio natural.

Estudos dessa natureza avaliativa devem ser incentivados em várias modalidades de produção de refeiçôes, considerando a relevância do segmento. Da mesma forma, o olhar crítico sobre o uso de embalagens na produção e na distribuição de refeições deve ser constantemente utilizado, visando açóes de planejamento de cardápios que possam gerar menos impactos negativos ao meio ambiente.

\section{REFERÊNCIAS}

ABERC - Associação Brasileira das Empresas de Refeições Coletivas. Dados de Mercado. Disponível em <http://www.aberc.com.br/mercadoreal.asp?IDMenu=21>. Acesso em: 09.10.2015.

ABNT - Associação Brasileira de Normas Técnicas. NBR 13230 - Simbologia indicativa de reciclabilidade e identificaçáo de materiais plásticos. Rio de Janeiro, ABNT, 1994.

NBR ISO 14001 - Sistemas da gestão ambiental: Requisitos com orientaçóes para uso. 2. ed. Rio de Janeiro, ABNT, 2004.

ABREU, E. S.; SPINELLI, M. G. N. A Unidade de Alimentação e Nutrição. In: ABREU, E. S.; SPINELLI, M. G. N; PINTO, A. M. S. Gestáo de Unidades de Alimentaçáo e Nutrição: um modo de fazer. São Paulo: Metha, 2013. p. 35-42.

ADA - American Dietetic Association. Position of the American Dietetic Association: food and nutrition professionals can implement practices to conserve natural resources and support ecological sustainability. Journal of the American Dietetic Association, v. 107, n. 6, p. 1033-1043, jun 2007.

BRASIL. Presidência da República. Casa Cívil. Lei no 12.305, de 2 de agosto de 2010: Institui a Política Nacional de Resíduos Sólidos. Brasília, 2010. Disponível em: <http:// www.planalto.gov.br/ccivil_03/_ato2007-2010/2010/lei/l12305.htm>. Acesso em: 30.06.2015. 
CALIXTO, C. F. S. et al. Avaliação da quantidade de óleo de soja em refeições oferecidas em um restaurante universitário. Demetra: Alimentaçáo, Nutriçáo \& Saúde, Rio de Janeiro, v. 8, n. 1, p. 53-61, 2013.

CAPELINI, M. Potencialidade e aplicação da prevençáo de resíduos de embalagens: abordagem sobre o projeto do produto e o consumo. 2007. Tese (Doutorado em Ciências da Engenharia Ambiental) - Escola de Engenharia de São Carlos, São Carlos, 2007.

CARNEIRO, C. L. Gerenciamento integrado de resíduos sólidos e sua aplicabilidade em produção de refeições: um diálogo interdisciplinar. HOLOS, Natal, v. 1, p. 68-74, 2014.

CARNEIRO, C. M. L. et al. Diagnóstico dos resíduos sólidos produzidos no restaurante universitário da UFRN. In: ENCONTRO NACIONAL DE ENGENHARIA DE PRODUÇÃO, 30., 2010, São Carlos. Anais... São Carlos, SP: Associação Brasileira de Engenharia de Produção, 2010. Disponível em: <http://www.abepro.org.br/biblioteca/ enegep2010_TN_STO_121_788_17487.pdf>. Acesso em: 28 jun.2015.

CARVALHO, J. M.C. Logística. Lisboa: Edições Silabo, 2002.

CNTL - Centro Nacional de Tecnologias Limpas. Questóes Ambientais e Produção mais Limpa. Série Manuais de Produção mais Limpa. Porto Alegre, SENAI-RS, 2003.

CHAVES, G. L. D. et al. Diagnóstico da Logística Reversa na Cadeia de Suprimentos de Alimentos Processados no Oeste Paranaense. In: CONGRESSO DA SOCIEDADE BRASILEIRA DE ECONOMIA, ADMINISTRAÇÃO E SOCIOLOGIA RURAL, 43., 2005, Ribeirão Preto. Anais... Ribeirão Preto, SP: Sociedade Brasileira de Economia, Administração e Sociologia Rural, 2005. Disponível em: <http://sober.org.br/ palestra/2/699.pdf> Acesso em: 30 nov.2015.

COLARES, L. G. T.; FREITAS, C. M. Processo de trabalho e saúde de trabalhadores de uma unidade de alimentação e nutrição: entre a prescrição e o real do trabalho. Cadernos de Saúde Pública, Rio de Janeiro, v. 23, n. 12, p. 3011-3020, 2007.

COLTRO, L.; GASPARINO, B. F.; QUEIROZ, G. C. Reciclagem de Materiais Plásticos: A Importância da Identificação Correta. Polímeros: Ciência e Tecnologia, São Carlos, v. 18, n. 2, p. 119-125, 2008.

COM - Comissão das Comunidades Europeias. Relatório da comissão ao Conselho e ao Parlamento Europeu: Sobre a aplicação da Directiva 94/62/CE relativa a embalagens e resíduos de embalagens e seu impacto no ambiente, bem como sobre o funcionamento do mercado interno. Bruxelas, 2006. 11 p.

EDWARDS, J. S. A. The foodservice industry: Eating out is more than just a meal. Food Quality and Preference, v. 27, n. 2, p. 223-229, 2013. 
EIMPack - Economic Impact of the Packaging and Packaging Waste Directive. Literature Review. Lisboa: Instituto Superior Técnico, Universidade Técnica de Lisboa, 2011. 122 p.

FARMER, G. M.; STANIEWICZ, N.; MICHAEL, B.; WOJCIK, A.; LIM, Y., IVKOVIC, D.; RAJAKULENDRAN, J. Audit of waste collected over one week from ten dental practices: a pilot study. Australian Dental Journal, v. 42, n. 2, p. 114-117, 1997.

FEIL, A. A.; Spilki, F. R.; Schreiber, D. Análise global das características de frações de resíduos urbanos residenciais. Revista Brasileira de Ciências Ambientais, n. 38, p. 63$77,2015$.

FERNANDES et al. Biodiesel a partir de óleo residual de fritura: alternativa energética e desenvolvimento sócio-ambiental. In: ENCONTRO NACIONAL DE ENGENHARIA DE PRODUÇÃO, 28., 2008, Rio de Janeiro. Anais... Rio de Janeiro, RJ: Associação Brasileira de Engenharia de Produção, 2008. Disponível em: <http://www.abepro.org.br/ biblioteca/enegep2008_TN_STO_077_542_12014.pdf>. Acesso em: 4 abr.2016.

FORLIN, F. J.; FARIA, J. A. Consideraçóes Sobre a Reciclagem de Embalagens Plásticas. Polímeros: Ciência e Tecnologia, São Carlos, vol. 12, n. 1, p. 1-10, 2002.

GIL, A. C. Métodos e técnicas de pesquisa social. 6. ed. São Paulo: Atlas, 2008.

GOLDING, A. Reuse of Primary Packaging: Final Report. Part I - Main Report. Brussels, 1999. 107 p.

GRAU. Green Restaurants Association University. Green Restaurant Certification 4.0 Standards. 2015. Disponível em: < http://www.dinegreen.com/restaurants/standards.asp >. Acesso em: 02/05/2015.

HARMON, A. H.; GERALD, B. L. Position of the American Dietetic Association: Food and Nutrition Professionals Can Implement Practices to Conserve Natural Resources and Support Ecological Sustainability. J Am Diet Assoc., v.107, n.6, p.1033-1043, 2007.

\section{JACOBSEN, H.; KRISTOFFERSEN, M. Case Studies on Waste Minimisation}

Practices in Europe: Topic report 2/2002. Copenhagen: European Environment Agency, 2002. 52 p.

\section{KINASZ, T. R.; WERLE, H. J. S. Geração de resíduos sólidos em unidades de} alimentaçáo e nutriçáo: composição física, influência do tipo de cardápio e tipo de serviço de distribuição. Cuiabá, Conselho Regional de Nutricionistas 1a Região, 2008. Disponível em: <http://crn1.org.br/images/pdf/Elena_feijo/i_residuos_uan.pdf >. Acesso em: 10 nov. 2015 .

LAMBERT, J. L. et al. As principais evoluçóes dos comportamentos alimentares: o caso da França. Revista de Nutriçáo, Campinas, v. 8, n. 5, p. 577-591, 2005. 
LEAL, D. Crescimento da alimentação fora do domicílio. Segurança Alimentar e Nutricional, Campinas, v. 17, n. 1, p. 123-132, 2010.

LIMA, L. M.; CAIXETA FILHO, J. V. Conceitos e Práticas de Logística Reversa. Tecnologística, São Paulo, v. 4, n. 66, p. 54-58, 2001.

POSPISCHEK, V. S.; SPINELLI, M. G. N.; MATIAS, A. C. G. Avaliação de ações de sustentabilidade ambiental em restaurantes comerciais localizados no município de São Paulo. Demetra: Alimentaçáo, Nutrição \& Saúde, Rio de Janeiro, v. 9, n. 2, p. 595-611, 2014.

ROGERS, D. S.; TIBBEN-LEMBKE, R. S. Size and Importance of Reverse Logistics. In: . Going backwards: reverse logistics trends and practices. Reno: Reverse Logistics Executive Council, 1998. p. 1-32.

ROLIM, P. M. et al. Produção de resíduos sólidos em uma unidade de alimentação e nutriçáo hospitalar. Porto Alegre, Sociedade de Veterinária do Rio Grande do Sul, 2011. Disponível em: <http://www.sovergs.com.br/site/higienistas/trabalhos/10021.pdf>. Acesso em: 21 jul.2015.

ROSS, S.; EVANS, D. The environmental effect of reusing and recycling a plastic-based packaging system. Journal of Cleaner Production, v. 11, p. 561-571, 2003.

SILVA et al. Comparison of disposable and returnable packaging: a case study of reverse logistics in Brazil. Journal of Cleaner Production, v. 47, p. 377-387, 2013.

SMYTH, D. P.; FREDEEN, A. L.; BOTH, A. L. Reducing solid waste in higher education: the first step towards 'greening' a university campus. Resources, Conservation and Recycling, v. 54, p. 1007-1016, 2010.

SOUSA, L. et al. Avaliação da gestão de resíduos sólidos de restaurantes, bares e similares: um estudo de caso. In: SIMPÓSIO DE PÓS GRADUAÇÃO EM ENGENHARIA URBANA, 3., 2012, Maringá. Anais... Maringá, PR: Universidade Estadual de Maringá, 2012. Disponível em: <http://www.eventos.uem.br/index.php/simpgeu/simpgeu/paper/ download/881/778>. Acesso em: 10 nov.2015.

SOUZA, M. F. et al. Caracterização dos resíduos sólidos gerados em um restaurante universitário. In: CONGRESSO DE INICIAÇÃO CIENTÍFICA, 18., 2009, Pelotas. Anais... Pelotas, RS: Universidade Federal de Pelotas, 2009. Disponível em: <http:// wp.ufpel.edu.br/rhima/files/2010/09/CE_00861.pdf>. Acesso em: 21 jul.2015.

SPINELLI, M. G. N. Gestão ambiental. In: ABREU, E. S.; SPINELLI, M. G. N; PINTO, A. M. S. Gestão de Unidades de Alimentaçáo e Nutrição: um modo de fazer. São Paulo: Metha, 2013. p. 227-230. 
VAN BELLEN, H. M. Desenvolvimento sustentável: uma descrição das principais ferramentas de avaliaçáo. Ambiente \& Sociedade, São Paulo, v. 7, n. 1, p. 67-87, 2004.

VENZKE, C.S. A geração de resíduos em restaurantes, analisada sob a ótica da produção mais limpa. In: ENCONTRO NACIONAL DE ENGENHARIA DE PRODUÇÃO, 21., 2001, Salvador. Anais... Salvador, BA: Associação Brasileira de Engenharia de Produção, 2001. Disponível em: <http://www.abepro.org.br/biblioteca/ENEGEP2001_ TR104_0127.pdf>. Acesso em: 26 set.2015.

WANG, R. Investigations of Important and Effective Effects of Green Practices in Restaurants. Procedia - Social and Behavioral Sciences, v.40, p.94-98, 2012. 